\title{
Concerns of cerebrospinal fluid leak in aggressive expanded endonasal endoscopic approach for craniopharyngiomas
}

\begin{abstract}
Cerebrospinal fluid leak represents a frequent complication in Craniopharyngioma's Endoscopic Endonasal Approach. A descriptive observational investigation was performed in 50 adult patients operated of Craniopharyngiomas by aggressive Expanded Endonasal Endoscopic Approach (EEEA) in "Hermanos Ameijeiras" Hospital since 2010 to 2019 using nasoseptal flap. The $14 \%$ of all patients develop CSF leak and $85,7 \%$ of these cases had a great communication into third ventricle creating a cisternoventricular space. Was identified relation with tumor size, hypothalamic invasion and adhesion strength of tumour. Surgical cavity suffered hydrostatic and hydrodynamic pression than lead to CSF leak independent of multilayer reparation.
\end{abstract}

Volume 10 Issue 4 - 2020

Marlon Ortiz Machín, Omar López Arbolay Department of Neurological Surgery,"Hermanos Ameijeiras" Hospital, Cuba

Correspondence: Marlon Ortiz Machín, Department of Neurological Surgery, "Hermanos Ameijeiras" Hospital, Havana City, Cuba, Email marlonneuro@gmail.com

Received: June 04, 2020 | Published: August II, 2020

Keywords: Expanded Endonasal Endoscopic Approach (EEEA), Cerebrospinal fluid (CSF) leak

\section{Introduction}

Cerebrospinal fluid (CSF) fistula represents a more frequent complication in Endonasal Endoscopic Approach for Craniopharyngiomas than another skull base tumor. ${ }^{1,2}$ Komotar et al. ${ }^{4}$ report $14 \%$ in a metanalysis ${ }^{3}$ and Jeswani $26,3 \% .{ }^{4}$ In centers with great volumes of cases operated by endonasal endoscopic approach using nasoseptal flap refers $10,6 \%$ and $14 \%$ of incidence..$^{5-9} \mathrm{CSF}$ leak appears in some points of reparations between surgical cavity and nasosphenoidal space in few days after surgery. Hydrodynamics physic laws could explain this observation.

\section{Method}

A descriptive observational investigation about CSF leak was performed in 50 adult patients operated of Craniopharyngiomas by Expanded Endonasal Endoscopic Approach (EEEA) in Ameijeiras Hospital since 2010 to 2019. Statistics analysis was performed using IBM $^{\circledR}$ SPSS $^{\circledR}$ Statistics Program 23.0. To analyze factors associated with CSF leak was used Pearson's chi quadrate test with $\mathrm{p}<0,05$ of statistical significance. Viable nasoseptal flap was achieved in all cases and tumor size, hypothalamic invasiveness and adherence was analyzed.

\section{Results}

In our series of 50 patients operated by EEEA with aggressive philosophy $14 \%$ developed CSF leak in few days after surgery with a viable nasoseptal flap, similar to an others investigation. ${ }^{10-14}$ In $85,7 \%$ of cases was identified a great communication with third ventricle space (Table 1) creating a cisternoventricular cavity.

The source of cisternoventricular cavity depend of tumor size, hypothalamic involvement and adhesion strength of tumour. Cisternal and ventricular involvement was more frequent in patient with giant craniopharyngiomas and high hypothalamic invasiveness or adherence (Table 2).

Table I Relation of CSF leak and anatomical compartment involvement

\begin{tabular}{llllll}
\hline \multirow{2}{*}{$\begin{array}{l}\text { Compartment involvement in } \\
\text { tumour dissection }\end{array}$} & \multicolumn{2}{l}{ CSF leak } & & & \\
\cline { 2 - 5 } & No & $\%$ & Yes & $\%$ & \\
\hline Cisternal & 25 & $58,1 \%$ & 1 & $14,3 \%$ & \\
Cisternal and ventricular & 18 & $41,9 \%$ & 6 & $85,7 \%$ & 0,039 \\
Total & 43 & $100 \%$ & 7 & $100 \%$ & \\
\hline
\end{tabular}

\section{Discussion}

The creation of cisternoventricular cavity to the end of aggressive EEEA imply a new space that suffers the hydrostatic and hydrodynamic pression of the CSF. ${ }^{15,16}$

Hydrostatic pression: is the force that produce the weight of the liquid in the wall of the cavity. It is proportional with gravity, density and height, and mathematically is:

\section{Hydrostatic pression= density $\mathrm{x}$ gravity $\mathrm{x}$ height}

Hydrostatic pression is higher in the skull base than in cranial vault in stand position consequently the risk of CSF leak is greater. In CNS infection the great density of the fluid increases the risk of CSF fistula.

Hydrodynamic pression: is the force of liquid moving into the cavity, it is defined as velocities vectoral field in relation with fluid particles and a scalar pression field in different cavity points. The 
caudal is the quantity of fluid that pass through a point of the system in a time, example the quantity of CSF that courses into foramen of Monro in a minute. ${ }^{16}$

Expanded endonasal endoscopic approach is performed to remove great craniopharyngiomas and frequently third ventricle space is placed through supraselar cistern and a new compartment is created, cisternoventricular compartment. ${ }^{1,29,12}$

How is the influential of hydrodynamic pression in this new compartment?

If we apply the Continuity Fluid Laws in Monro's foramen, Silvio aqueduct and Surgical Cavity then:

Table 2 Relation of anatomical compartment involvement with size, hypothalamic invasion and tumor's adherence

\begin{tabular}{|c|c|c|c|c|c|c|}
\hline \multirow[b]{2}{*}{ Variable } & & \multicolumn{4}{|c|}{ Compartment involvement in tumour dissection } & \multirow[b]{2}{*}{$\mathbf{P}$} \\
\hline & & Cisternal $(\mathbf{N}=26)$ & $\%$ & $\begin{array}{l}\text { Cisternal and Ventricular } \\
(\mathrm{N}=24)\end{array}$ & $\%$ & \\
\hline \multirow{3}{*}{ Size } & Small & 10 & $38,5 \%$ & 2 & $8,3 \%$ & \multirow{3}{*}{0,000} \\
\hline & Medium- Large & 15 & $57,7 \%$ & 10 & $41,7 \%$ & \\
\hline & Giant & I & $3,8 \%$ & 12 & $50 \%$ & \\
\hline \multirow{3}{*}{$\begin{array}{l}\text { Hypothalamic } \\
\text { Invasion }\end{array}$} & Grade 0 & 17 & $65,3 \%$ & 4 & $16,7 \%$ & \multirow{3}{*}{0,003} \\
\hline & Grade I & 6 & $23,1 \%$ & 10 & $41,7 \%$ & \\
\hline & Grade 2 & 3 & $11,5 \%$ & 10 & $41,7 \%$ & \\
\hline \multirow{4}{*}{ Adherence } & Loose & 23 & $88,5 \%$ & 3 & $12,5 \%$ & \multirow{4}{*}{0,000} \\
\hline & Tight & 1 & $3,8 \%$ & 7 & $29,2 \%$ & \\
\hline & Fusion & 2 & $7,7 \%$ & 8 & $33,3 \%$ & \\
\hline & Replacement & 0 & $0 \%$ & 6 & $25,0 \%$ & \\
\hline
\end{tabular}

Caudal in Monro = Caudal in Silvio= Caudal in Surgical Cavity

Area of Monro $x$ Velocity $=$ Area of Silvio $x$ Velocity $=$ Area of Surgical Cavity $x$ Velocity

As Monro's foramen, aqueduct of silvio and surgical cavity have different dimensions to establish this equality is necessary that the liquid increase or diminish the velocity in different points. Example, increases in Monro point and diminish surgical cavity point.

Bernoulli's theorem relate Energy Conserve Law with hydrodynamic system, and refers that addition of kinetics, gravitational energy and intrinsic pression is same in different points of the system, mathematically:

$$
K E_{1}+G P E_{1}+P_{1}=K E_{2}+G P E_{2}+P_{2}
$$

If we consider Foramen of Monro as point 1, Surgical Cavity as point 2 and valued that Gravitate Potential Energy in a patient with supine position with 30 grades flexion of the head is same in Monro and Surgical Cavity point them:

$$
\begin{aligned}
& K E_{1}+G P E_{1}+P_{1}=K E_{2}+G P E_{2}+P_{2} \\
& K E_{1}+P_{1}=K E_{2}+P_{2} \text {, if is used the equation of Kinetic Energy: }
\end{aligned}
$$

$1 / 2$ Density $_{1} x$ Velocity $_{1}^{2}+P_{1}=1 / 2$ Density $_{2} x$ Velocity $_{2}^{2}+P_{2}$, but the density is same in all point of the hydrodynamic system:

$$
1 / 2 \text { Density }_{1} x \text { Velocity }_{1}^{2}+P_{1}=1 / 2 \text { Density }_{2} x \text { Velocity }_{2}^{2}+P_{2}
$$

Finally, there are two variables in balance, velocity and pression of the liquid. Previously was defined that velocity of the liquid was higher in Monro's point than in Surgical Cavity point, therefore to stablish Bernoulli theorem equality the pression in Surgical Cavity is higher than in Monro point.
The increases of liquid pression into surgical cavity doesn't appear immediately at the end of surgery due to it is leaving during the procedure, it appears 48 hours after surgery and is considered like hydrodynamic effect, and could explain clinical symptoms, and CSF leak late after surgery. We suggest that skull base reparation should be with multilayer components, included fat, fascia and glue it is always associated with nasoseptal flap. If dissection involve only cisternal spaces then lumbar drainage during $72 \mathrm{~h}$ could be beneficious, however in giant tumor with high invasiveness is necessary contemplate about the reduction of ventricular pression before tumor surgery, using different method described.

\section{Conclusion}

A cisternoventricular cavity created in aggressive EEEA for great and invasiveness craniopharyngiomas suffers a late hydrodynamic effect that increase local pression and could favour of CSF leak independently of skull base multilayer reparation.

\section{Acknowledgments}

None.

\section{Conflicts of interest}

The authors declare no conflicts of interest.

\section{References}

1. LópezArbolay O, Lobaina Ortiz M, Ortiz Machín M. Craniopharyngiomas Risks and challenges of the Extended Endoscopic Endonasal Approach to the Skull Base. Rev Chil Neurocirugía. 2014;40:12-17.

2. Ortiz Machín M, López Arbolay O, Cruz Pérez P. Nuances of the extended 
endoscopic endonasal approach in the excision of craniopharyngiomas Rev Chil Neurocirugía. 2017;43:128-133.

3. Komotar JR, Kellner CP, Bruce JN. Update on the Surgical Management of Craniopharyngiomas. US Neurology. 2010;6(1):99-104.

4. Jeswani S, Nuño M, Wu A, et al. Comparative analysis of outcomes following craniotomy and expanded endoscopic endonasal transsphenoidal resection of craniopharyngioma and related tumors: a single institution study. J Neurosurg. 2016;124(3):627-638.

5. Kassam AB, Gardner PA, Snyderman CH, et al. Expanded endonasal approach, a fully endoscopic transnasal approach for the resection of midline suprasellar craniopharyngiomas: a new classification based on the infundibulum. J Neurosurg. 2008;108(4):715-728.

6. Cavallo LM, Prevedello DM, Solari D, et al. Extended endoscopic endonasal transsphenoidal approach for residual or recurrent craniopharyngiomas. J Neurosurg. 2009;111:578-589.

7. Gardner PA, Kassam AB, Snyderman $\mathrm{CH}$, et al. Outcomes following endoscopic, expanded endonasal resection of suprasellar craniopharyngiomas: a case series. J Neurosurg. 2008;109:6-16.

8. Cavallo LM, Frank G, Cappabianca P, et al. The endoscopic endonasal approach for the management of craniopharyngiomas: a series of 103 patients. J Neurosurg. 2014;121(1):100-113.

9. Morisako H, Goto $\mathrm{T}$, Goto $\mathrm{H}$, et al. Aggressive surgery based on an anatomical subclassification of craniopharyngiomas. Neurosurg Focus. 2016;41(6):E 10.
10. Pascual JM, Prieto R, Carrasco R, et al. Craniopharyngiomas adherence to the hypothalamus. Neurosurg Focus. 2014;37(2):1-9.

11. Prieto R, Pascual JM, Rosdolsky M, et al. Craniopharyngioma adherence: a comprehensive topographical and outcome related risk stratification model based on the methodical examination of 500 tumors. Neurosurg Focu.s 2016;(6):E13.

12. Hadad G, Bassagasteguy L, Carrau RL, et al. A novel reconstructive technique after endoscopic expanded endonasal approaches: vascular pedicle nasoseptal flap. Laryngoscope. 2006;116(10):1882-1886.

13. Puget S, Garnett M, Wray A, et al. Pediatric craniopharyngiomas: classification and treatment according to the degree of hypothalamic involvement. J Neurosurg. 2007;106:3-12.

14. Wijnen M, Olsson DS, van den Heuvel-Eibrink MM, et al. Excess morbidity and mortality in patients with craniopharyngioma: a hospitalbased retrospective cohort study. Eur J Endocrinol. 2018;178:95-104.

15. Valle FR. Experimental hydraulics during the 18th century in France. Hydraulic and environmental engineering. 2016;37(3):113-126.

16. Valle FR. Background of the well-known Bernoulli equation. Hydraulic and environmental engineering. 2020;41(1):71-84. 